\title{
Impacts of Cloud Classroom on the Communication of Higher Education in the Time of Educational informatization
}

\author{
Yuhan Wu \\ (Heilongjiang University)
}

\begin{abstract}
Educational informatization is the internal requirement of constructing a modern education system, forming a learning society, promoting scientific and technological innovation, and promoting social harmony. Accelerating educational informatization is a strategic choice to promote the reform and development of China's education. The new media, represented by Internet plus, as the new driving force of educational informatization, provides the condition guarantee for the deep integration of information technology and education, and puts forward new requirements for the goal of personnel training, providing a means support for the realization of new learning methods, and providing technical support for the construction of modern learning environment. Cloud classroom as a new means of education media, its application also provides a new possibility for online education online courses, and it is also an opportunity for education communication.
\end{abstract}

Keywords : education informatization; education communication; cloud classroom

DOI : $10.36012 /$ fhe. v2i3. 2770

\section{The current situation of cloud classroom un- der the information - based education}

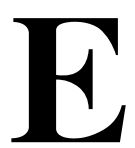

ducation informationization is the internal requirement of constructing a modern education system, forming a learning society, promoting scientific and technological innovation, and promoting social harmony. Accelerating education's informationization is a strategic choice to promote the reform and development of education in China. The new media represented by "Internet + ", as the new driving force of educational informatization, provides conditions for the deep integration of information technology and education, puts forward new requirements for talent training objectives, provides means to support the realization of new learning methods and provides technical support for the construction of modern learning environment. ${ }^{[1]} \mathrm{As}$ a new means of education media, the application of cloud classrooms also provides a new possibility for online education network courses. It is also an opportunity for educational communication.

The respondents of this questionnaire about cloud classroom network teaching environment in colleges and universities were 50 students from 3 colleges and universities in the province, and the questionnaire recovery rate was $100 \%$. The survey mainly includes the conditions of network teaching in colleges and universities, the use of " cloud classroom" of network teaching resources in colleges and universities, the evaluation and primary effect of network teaching application, etc. According to the survey, the online teaching environment in colleges and universities is as follows :

First, network operation (including network operation speed, stability and network security). 
Students were asked to evaluate the network situa- $\quad$ tion on four levels, as shown in Figure $1-1$.

\section{Table 1: Network operation}

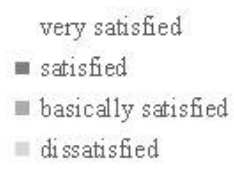

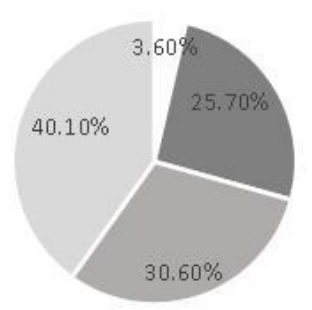

\section{Table 1}

According to the survey results, only $3.6 \%$ of el. The existing network facilities cannot meet the students are very satisfied with the operation of cloud classrooms, $25.7 \%$ are satisfied, and $40.6 \%$ are basically satisfied, and $30.1 \%$ are dissatisfied. The results show that the operating conditions and security of cloud classroom networks in colleges and universities have not reached a satisfactory levincreasing demand for bandwidth.

Second, the resources inside the cloud classroom of online teaching. We asked students to evaluate online teaching resources from four levels, and the overall situation could be understood by way of Figure 1-2.

\section{Table 2: Resources inside the cloud classroom for online teaching}
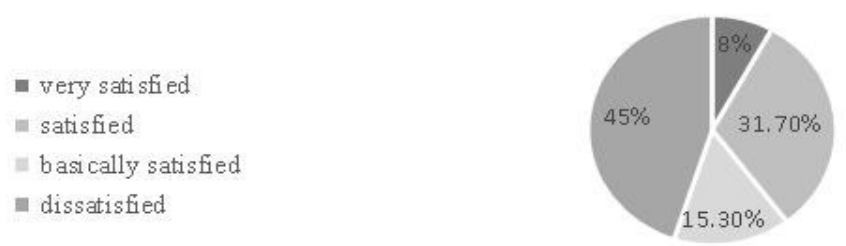

\section{Table 2}

The survey results show that only $8 \%$ of the students are very satisfied with the cloud classroom resources, $31.7 \%$ are satisfied, and $15.3 \%$ are basically satisfied, and $45 \%$ are dissatisfied. This shows that the cloud classroom is still in the initial stage of popularization, and many functional resources need to be enriched, course resources and learning resources need to be improved, and course resources are not targeted enough.

Thirdly, the teaching effect of network cloud classroom. We divided the students into four levels from three aspects to evaluate the impact of online teaching. Figure $1-3$ shows the overall situation.

\section{Table 3: The teaching effect of network cloud classroom}
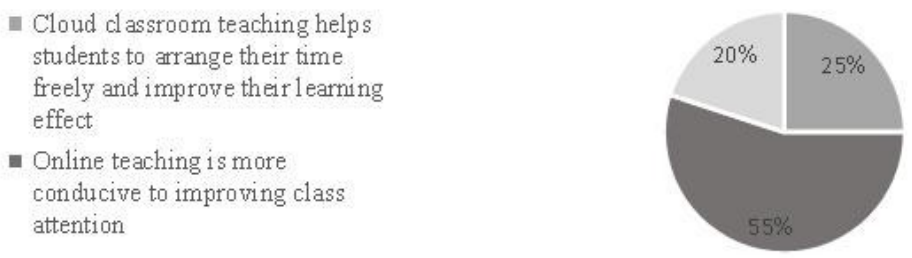

Table 3 
Results of an investigation of students on classroom teaching evaluation in the three projects show that respondents account fora proportion of over $60 \%$, and $25 \%$ of the students thought that " cloud of classroom teaching is conducive to students' free time, to improve learning effect", while nearly $55 \%$ of the students thought that "the network teaching is more advantageous to improve the classroom attention". Another 20\% of the students think network learning convenient communication between teachers and students. This indicates that most students maintain a favorable attitude towards cloud classroom teaching, believ- ing that cloud classrooms can facilitate students to effectively use their scattered time to improve classroom efficiency and attention. However, some students also believe that the adoption of cloud classrooms is not conducive to the interaction between teachers and students, and there are some drawbacks.

Fourthly, students' attitude towards the network cloud classroom teaching. In combination with Figure 1-3, we evaluate the degree of liking and acceptance of cloud classroom teaching at four levels. Students' attitudes to cloud classroom teaching can be understood through Figure 1-4.

\section{Table 4: The students' attitude to the network cloud classroom teaching}

$$
\begin{aligned}
& \text { = enjoy } \\
& \text { = like } \\
& \text { = dislike } \\
& \text { m disgust }
\end{aligned}
$$

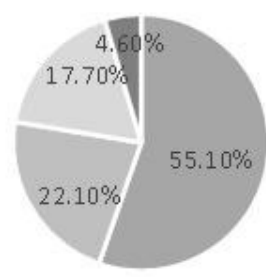

Table 4
The survey results show that nearly $77.7 \%$ of students are very fond of cloud classroom teaching, $17.7 \%$ dislike it, and only $4.6 \%$ dislike it very much. This also indicates that most students like and accept the overall feelings of cloud classroom teaching. That cloud classroom has many advantages that offline teaching cannot achieve and is unique.

Through this questionnaire survey and chart analysis, we can summarize several unique advantages and existing problems of online teaching.

\section{1 Development advantages of cloud classroom}

1.1. 1 The curriculum is flexible and convenient for students to arrange their time freely. Cloud classroom network teaching can save students' travel time, and the break time is more convenient for students to arrange their own learning time.
According to the investigation, the large and cloudy classroom APP on the market now provides a student playback function, which is convenient for students to study independently, review independently, and flexibly arrange their own learning time. Learning is no longer limited by time and space and can be learned anytime and anywhere as the most significant advantage of cloud classroom APP.

1. 1. 2 Software is powerful, and big data saves time in quantifiable ways. Cloud APP in class not only provide the teachers and students in the teaching of video voice function, more class attendance, homework, the application even the wheat, classroom questioning, diversified functions such as information sharing, colorful function not only improve the efficiency of the teacher's classroom 
management, teaching but also add to the students ' learning interest, let students enjoy different from online teaching resources brought by the powerful network function convenience and resource sharing. The use of big data can more quantify attendance and activity as an important standard for evaluation of performance so as to make teaching more fair and just.

1. 1. 3 Reduce interference factors and improve students' classroom attention. The use of online cloud classrooms eliminates the spatial disadvantages brought by offline class teaching. The offline classroom environment is difficult to ensure stability due to uncontrollable factors, such as classroom atmosphere and mutual interference between students. Online teaching can solve this problem very well. Under online teaching, all students are independent individuals with their own independent learning space without interfering with each other, effectively improving students' attention in class and attention to teachers' teaching content.

\section{2 Problems faced by network cloud classroom teaching}

1.2. 1 Limited extension of teaching media and uneven distribution of educational network resources. After stepping into the era of "Internet +" new media, "cloud classroom" as a new means of network classroom, with the outbreak of the epidemic, its wide application is more imminent. At the present stage, colleges and universities across the country have taken the new media "cloud classroom" as the main media form of information release, educational resource sharing, and distance learning. They have successively emerged many functional distance learning apps, such as spike, youdao quality course, zhizhidao, and other application software online course platforms. But even so, there are still many phenomena such as the collapse of the online course platform and the collapse of the online course platform due to the over- crowding of online course software and the overcapacity of online course software. The instability of the mobile network also makes the teachers and students in universities miserable. Due to the shortage of new media apps and limited choices of teachers and students, the instability of mobile networks has increasingly become a stumbling block to the widespread application of "cloud classroom".

Under the background of the information age, public information resources are of great significance to everyone. Public information resources mean that people have equal access to rights and possibilities. In the field of education, educational information-based resources as the cornerstone of information - based education have a great impact on the promotion of network distance education. ${ }^{[2]}$ At present, in our society, the contradictions and problems caused by the uneven distribution of public information resources between urban and rural areas are more prominent. There is still a significant gap in the allocation of educational resources between urban and rural areas and the popularization of new media software. The uneven distribution of educational resources has been restricting the development of education levels for a long time. There are apparent differences in the popularity of network technology and the supply rate of educational equipment between urban and rural areas, which is also one of the manifestations of the limited extension of teaching media and the difficulty of "cloud classroom" in the in-depth educational communication.

1.2. 2 The traditional teaching model is deeply rooted, and the media application ability of teachers and students is insufficient. From the rise of a private school in the Spring and Autumn Period and the Warring States period to the birth of the Imperial School, from the rise of the examination 
system in the Han Dynasty to the popularity of the imperial examination system in the Tang Dynasty, from the rigid eight-track selection system in the Ming and Qing Dynasties to the use of The Comenius class teaching system in 1862 . There is no denying that impartation teaching has become the standard teaching pattern of teachers and students in colleges and universities in China, and there has been no essential reform. Many teachers and students in colleges and universities have been accustomed to the traditional lecturing style of teaching and thus resist the "invasion" of the new media network platform. At the same time, the push mode of traditional paper media also affects public perception. With the emergence of new network communication technologies, the boundary between the communication subject and the audience is increasingly blurred, and the audience's rejection, resistance, and lack of attention to the "cloud classroom" of new media due to traditional concepts have also become a significant bottleneck in today's scholarly communication.

With the development of educational informatization, new media has gradually replaced traditional media, and network teaching has become an important branch of educational teaching to carry out educational communication. For teachers and students of colleges and universities, the new teaching model is different from the traditional teaching model. As an emerging medium, the " cloud classroom" of new media has more vital interaction, immediacy, and creativity, which requires teachers and students of colleges and universities to control and control the new media. Nowadays, it is still common for some teachers to lack the ability of new media network operation and application due to the limitation of The Times or lack of corresponding training. Some teachers lack the specific design of systematic teaching design due to the application of "cloud classroom", and systematic teaching activity design is not standardized, and so on. This kind of inadaptability to new educational media is also one of the bottlenecks of " cloud classroom" scholarly communication under the background of informatization.

1. 2. 3 It isn't easy to effectively monitor students' learning environment and ensure their learning quality. Although online " cloud classroom" teaching brings full convenience to teachers and students, no matter what kind of online classroom APP can observe and control each student's state of attending class. Although different from real class teaching, network teaching provides quick check - in, the application even the wheat, online questions, relatively convenient education function, such as reserved homework. Still, because APP network capacity limit, achieve smooth $\mathrm{BuKa}$ is very rare, hard to require all the classes open cameras, all- round observation students' dynamic moment, it also requires students to have autonomy and self-control to achieve comparable offline teaching the teaching effect. ${ }^{[3]}$ Outbreak during the national college students a lesson, which makes the utilization rate is not high in the network classroom "cloud" was forced to lead to, nailing, learning through Caton often occurred frequency hot search. Online classes APP quality problem has become a new issue, including the Tencent emergency capacity to support network teaching, Ali's emergency workers to maintain supply network class. Still, issues like the full $\mathrm{O}^{-}$ pening of network cameras remain unsolved.

Not only that, some students of the campus environment, the family environment can't be compared with the family environment is not controllable factors, different students have a different family environment and learning environment. A case in point was our ancient philosopher Mencius. His 
mother moved three times for his son to enjoy a favorable study environment. One of the related famous verse was, "When one is surrounded by the virtuous, he'll become upright himself, " showing the importance of learning environment on development, thanks to the flexibility of online teaching space also inevitably lead to some factors, lead to relative inequality of education.

For the "cloud classroom" of online teaching, students' self - control is basic and teacher student and interpersonal interactions are complicated. Facing the problem of not being able to go back to school, although cloud classrooms can provide students with basic classroom teaching, they cannot guarantee students' learning efficiency. Teachers are in a state of invisible, students in a free environment. Self-discipline becomes the key to the students learning, students can't go to the library to study, general lack of good learning environment, teachers can't do in-class quizzes, real - time monitoring, online exam plagiarism is inevitable. Teaching quality is hard to quantify, learning situation cannot be measured, and not easy to evaluate students in the job, nip in the bud. Although teachers and students can interact online, they cannot have close face - to - face contact, intricate problems are difficult to ask questions in real - time, and problems cannot be effectively solved after class. As a result, the backlog of problems is not conducive to the improvement of students' learning quality. The lack of offline contact is not conducive to face - to - face social contact, may cause interpersonal interaction problems, is not conducive to the maintenance of interpersonal relations and the corresponding competitive incentives, is not conducive to improving learning quality.

\section{2. the impact of cloud classrooms on the dis- semination of educational information}

\section{1 The influence on the teachers group}

We should change teachers' teaching methods and urge them to improve their information application ability to adapt to the spread of educational information. Unlike traditional class - based classroom teaching, teachers impart knowledge to students through books, and online teaching puts forward higher requirements for teachers' professional development ability. As educators in the new era, college teachers should have certain information technology abilities and be able to skillfully use basic network equipment, such as WPS, MS OFFICE, and other basic software. This requires college teachers to continuously improve their self - ability to adapt to the development of the "Internet + " environment. Under the new media education informatization horizon, students have more options, no longer had a strong dependence on teachers, students access to resources channels increasingly affluent, way more diverse, can according to oneself circumstance to arrange my study plan, strategy and time, and teachers leading from the traditional model of classroom gradually for students learning guides to assist. Still, no doubt, with the diversity of students learning resource options also indirectly force teachers must improve their professional ability and the breadth of knowledge, ability in big data under the impact of informatization in an impregnable position. ${ }^{[5]}$

\section{2 The impact on the student body}

Assist students in making study plans and urge students to study independently to adapt to the spread of educational information. Students more say, along with the development of the new media era from the old traditional classroom relatively passive recipients " master" gradually evolved into the school, classroom, and cloud immediacy and helping teachers need to realize from 
the original "what teachers teach, students learn what" to "what students want to know, what teacher professor" shift, scaffolding teaching, guide students to take the initiative to find problems, teachers take a back seat is responsible for the answer of the course content. Cloud class to assist students in customizing the most suitable for their learning plan, according to the difficulty of students' knowledge level for adjustment, personalized recommendation, the teacher can also through the network platform of sizeable statistical data feedback to formulate the most suitable for students of class teaching mode, realize the winwin between teachers and students, the students engaged enhanced at the same time, to better promote the student's understanding of knowledge content, to improve the students' learning efficiency and learning level.

\section{3 The influence on classroom teaching methods}

We should guide the reform of teaching methods and realize the diversification of learning to adapt to the spread of educational information. It cannot be denied that in the Internet era, the hybrid teaching model, which is dominated by independent online exploration and supplemented by offline interactive discussion, will replace the traditional offline classroom teaching mode, which is also the trend of the information age. The application and development of new media enable university teachers to interact online through WeChat, QQ, learning pass, MOOC, and other network platform functional software. Application of new media also provides the guarantee for "flip" class, this is not only the change of teaching tools, teacher to student's education also gradually pay attention to interact with the students of the class, students can discuss with the teacher in real-time employing text messaging, and they can also learn through the video and voice calls and the corre- sponding transfer teacher face to face. The teacher can also teach through the network learning platform to supervise students' learning process and take advantage of big data, saving class attendance time, mobile headcount, and improve college students' attendance. The network platform's playback function also makes up for the time-limited nature of traditional teaching so that students can use the "cloud" to review what they have learned at any time in their spare time to achieve better hybrid learning.

\section{The future significance of cloud classroom for educational communication}

\section{1 Break the space-time boundary of teaching and realize resource sharing}

Through the cloud classroom, the teacher can take this class is to teach the class content via live and recorded video terminal transmission to the network system of the mobile terminal to realize the cloud classroom interaction between teachers and students, the classroom. Through a variety of cloud APP reserve a prelab assignment group signed in realizing the teaching task of preparation before class and review after class and homework decorate work, comprehensive and effective implementation class, class, class combination, also makes the teachers before class, after class teaching under the guidance of possible. On the one hand, teaching is not limited to the 45 minutes of a school class. The interaction between teachers and students breaks the previous time limit through the interaction and discussion function in class supported by the network platform. On the other hand, the resource sharing of online courses also serves all kinds of schools at all levels. Students of ordinary institutions of higher learning can obtain the educational resources of first - class universities, 985 and 211 colleges, and carry out knowledge co- construction with the help of cloud clas- 
ses to break the barriers and space restrictions between original regions and colleges and carry out cultural exchanges.

\section{2 To promote personalized learning and realize} program teaching

Because the physical and mental development of people is different and uneven, so teachers in order to better teaching in traditional teaching should pay more attention to the difference and imbalance of individual students. In traditional large class teaching, because of the huge numbers of students, teachers can't take care of every student to realize in the true sense of their aptitude, the emergence of cloud classroom just makes up for the lack of teachers in the teaching and learning of personalized, cloud classroom big data through the network, students can learn through the cloud classroom reservation for their diversity, better learning. For those students with weak professional foundations and those with excellent professional foundations, the application of cloud classrooms realizes personalized program teaching under the background of educational informatization. ${ }^{[4]}$ These clouds can develop different types of students, the varying degree students the biggest multiple potentials, able to meet the learning needs of students and to use of big data, such as artificial intelligence technology in the students learning outcomes for professional evaluation, analysis, forecast, and feedback, to push for its targeted learning resource bundles, realizing the accurate, personalized teaching and self-study.

\section{Future development measures and prospects} of cloud Classroom education communication

\section{1 Strengthening organizational support to ensure} the suspension of classes in poverty - stricken areas

To make the distribution of educational resources more reasonable and promote the fairness of education, local governments should strengthen the educational radiation to the remote mountainous areas, poor rural areas, and surrounding cities, and increase the organizational guarantee to improve the educational capacity of poor areas. In the face of emergencies, small towns and villages are unable to implement the network terminal platform to teach, which will virtually open a gap with urban children. Despite the great efforts of the state to lift people out of poverty and strengthen poverty and the improvement of educational conditions in rural areas, many poor counties and villages still lag behind big cities and megacities in terms of infrastructure, network, and communication. At present, there are still many rural areas without mobile Internet and broadband, so that distance education can not be taught online. Teachers and students in universities are prohibited from staying in school except for special circumstances. In the face of emergencies, students cannot return to school, but at the same time, smooth Internet access and popularization of cloud classes are imminent. Countries should step up to the poor areas, the rural education investment ratio, to ensure that "every family has a network, the neighborhood lton-us", all regions should also attach great importance to the poor places emphasis on this area, in the case of security "closed is not suspended," at the same time, it is necessary to strengthen the education of poor local coordination ability, emergency contingency ability, network technology, improve poor areas when dealing with the sudden outbreak of comprehensive education system response capacity.

\section{2 Break the shackles of traditional ideas and im-} prove the quality of teachers information application

In the information - based environment, teachers should break the original concept confined to the traditional textbooks in the real classroom, have the courage to take the first step to keep up 
with the pace of The Times, actively adapt to the network cloud platform, master relevant information technology and network application ability and have to carry out important decisions, which make up for the offline education that cannot be carried out normally. With the continuous integration of the Internet, big data, cloud platforms, artificial intelligence, and education, the era of "Internet + education" has also come. The degree of social informatization is deepening. With the continuous popularization of smart mobile devices and mobile phones, online classes through mobile apps have become the times' mainstream. The outbreak of the epidemic is like a "fuse" and a "catalyst". The Times and emergencies do not allow us to continue to watch and wait, and the online education network platform "cloud classroom" has been put into use on a large scale. The blended teaching model of online education and offline education has been widely valued and applied. However, for a long time, offline classroom teaching and generation gap and abandonment of online education have not become a common demand of the public, leading to some old university teachers' inability to adapt to the information environment of education and their anxiety. Therefore, the cultivation of teachers' information application literacy is "on the way and has to be started".

\section{3 VR live - action technology is adopted to make distance education more vivid}

In the information age of education, big data + artificial intelligence + Internet makes it possible for online education "cloud classroom" to be applied in distance education. VR technology virtual reality is the ultimate application form of multimedia. It crystallizes the rapid development of sensing technology, artificial skills, robot technol- ogy, and other multi - technical and scientific fields. ${ }^{[6]}$ Using the VR technology for remote teaching, the students can see the teacher in network terminal and the synchronization of the other side of the voice, and through careful capture transferred to virtual reality synchronous broadcasting room, students can also through VR immersive feeling is like a body in classroom teaching, enhance students' learning engagement, it will be a "cloud" class a comprehensive network platform, and experience more upgrade, can not only solve the interaction problem between teachers and students more can promote teachers to monitor the situation of students' learning, realize the comprehensive monitoring the quality of teaching.

\section{References}

[1] Jianjun Wang. What kind of education reform is more likely to promote the change of teachers $[\mathrm{J}]$. Shanghai Educational Research,2007(05).

[2] Hong Tian. Problems and Countermeasures of Experimental Teaching in Colleges and Universities $[\mathrm{J}]$. Experimental Science and Technology,2014(01).

[3] Shengquan Yu. Promoting the Two-way Integration of Technology and education - - Interpretation of The Ten-year Development Plan for Educational Informatization (2011-2020) [J]. China Audio-Visual Education, 2012(05).

[4] Zhizhen Zhang, Zhang Lingling, Li Mang. Analysis of the Application of Artificial Intelligence in Education: the Inevitability and Possibility of Teaching Automation [J]. China Distance Education, 2019(01).

[5] Yi He. Research on the Precise Practice Teaching Model of "Internet + Artificial Intelligence" $[\mathrm{J}]$. Chinese Journal of Multimedia and Network Teaching (the ten-day issue),2020(03).

[6] Dongfeng Gao. Requirements, Ideas and Paths of Experimental Teaching Reform in Universities in the Information Age $[\mathrm{J}]$. China Higher Education Research, 2018(03). 